International Journal of Current Advanced Research

ISSN: O: 2319-6475, ISSN: P: 2319 - 6505, Impact Factor: SJIF: 5.995

Available Online at www.journalijcar.org

Volume 6; Issue 4; April 2017; Page No. 3371-3373

DOI: http://dx.doi.org/10.24327/ijcar.2017.3373.0276

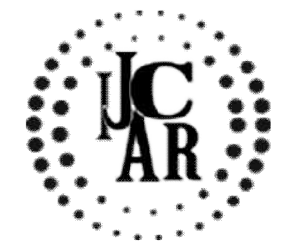

Research Article

\title{
KNOWLEDGE, ATTITUDE AND PRACTICE ON ORAL HYGIENE MEASURES AMONG ADOLESCENTS IN SEMI-URBAN AREAS
}

\author{
Shebi $S^{*}$., Anand $S$ and Dhanaraj $M$
}

Department Of Prosthodontics, Saveetha Dental Collage and Hospitals, Chennai 77

\begin{tabular}{l}
\hline A R T I C L E I N F O \\
\hline Article History: \\
Received $20^{\text {th }}$ January, 2017 \\
Received in revised form $19^{\text {th }}$ February, 2017 \\
Accepted $22^{\text {nd }}$ March, 2017 \\
Published online $28^{\text {th }}$ April, 2017 \\
\hline
\end{tabular}

\section{Key words:}

Oral Hygiene Measures, Semi-Urban Areas

\begin{abstract}
A B S T R A C T
Aim: To assess the knowledge oral hygiene practice among adolescents residing in semi urban areas.

Background: Oral hygiene knowledge contributes to good oral health, but unless attitudes and habits are developed and put into practice, little will be gained.It is important to review the knowledge, attitude, and practices of the oral health of adolescents, even though they are educated, with the objectives of inculcating healthy life style practices to last for a lifetime. Individuals who hold favorable oral health related beliefs over time have better oral health in their later years than those who do not. This implies that changing beliefs should result in changes in behaviors.

Methodology: A descriptive cross sectional survey was conducted in the self administered questionnaire that assessed the knowledge, attitude and practice on oral hygiene measures among 100 adolescents residing in semi urban areas of Chennai. The results weren't analysed by descriptive statistics method.

Results: Most of the students residing in semi- urban areas have knowledge about cleaning their teeth and tongues except the knowledge about interdental aids and in the use of mouthwash. And most of them cleaned their teeth using tooth brush and tooth paste.

Conclusion: The toothbrush with toothpaste is the most common oral hygiene aid used for cleaning teeth, it was observed that a greater number of students brushed their teeth twice daily.
\end{abstract}

Copyright $₫ 2017$ Shebi $\boldsymbol{S}$ et al. This is an open access article distributed under the Creative Commons Attribution License, which permits unrestricted use, distribution, and reproduction in any medium, provided the original work is properly cited.

\section{INTRODUCTION}

Oral diseases have been a persistent public health problem globally, with almost every individual experiencing poor oral health at least once in their life time $(1,2)$. Oral health is a state of being free from chronic mouth and facial pain, oral and throat cancer, oral sores birth defects such as cleft lip and palate, periodontal disease, tooth decay and tooth loss, and other diseases and disorders that affect the oral cavity $(3,4)$. Oral health affects the general health, well-being, education and development of children and their families (5), and diminishes the quality of life $(6,7)$. Chronic oral infections can pose a risk for diabetes, cardiovascular diseases like stroke, respiratory diseases, low birth weight, preterm births $(8,9)$. Oral conditions affect 3.9 billion people globally; the global burden of which increased 20.8\% from 1990-2010 (10). Untreated caries in permanent teeth was the most prevalent conditionfollowed by severe periodontitis and untreated caries in deciduous teeth (11). Oral disease burden is significantly higher among poor and disadvantaged population with an increase in developing countries (12).

*Corresponding author: Shebi S

Department Of Prosthodontics, Saveetha Dental Collage and Hospitals, Chennai 77
Globally, poor oral hygiene occurring due to increasing plaque and calculus deposits with increasing age have been reported among children and adolescents (13). India, sixth biggest country by area is the second most populous country. Factors contributing to the steady rise in prevalence of periodontal disease include poor oral health awareness. Oral health knowledge is considered to be an essential prerequisite for health-related behaviour. Although only a weak association exists between knowledge and behaviour in crosssectional studies, there are studies that establish an association between knowledge and better oral health (14). Oral health is significantly related to oral health behaviours and their knowledge. Oral health knowledge contributes to good oral health, but unless attitudes and habits are developed and put into practice, little will be gained. It is important to review the knowledge, attitude, and practices of the oral health of adolescents, even though they are educated, with the objectives of inculcating healthy lifestyles practices to last for a lifetime. Individuals who hold favourable oral health related beliefs over time have better oral health in their later years than those who do not. This implies that changing beliefs should result in changes in behaviours (15). 


\section{METHODOLOGY}

A questionnaire was distributed among the adolescents residing in Chennai and was asked to fill it and return. Sample size of the study is 100 . Total of 15 questions was included regarding the oral health practices among the adults questionnaire were explained whenever necessary, and the participants were given assurance regarding confidentiality of their responses and were requested to mark their answers and complete it individually. Students knowledge, attitude and practices were assessed by using a questionnaire which includes the following

- Do you clean your teeth?

- How often do you clean your teeth?

- What type of brush do you use?

- Which technique do you use for brushing ?

- When do you change your tooth brush?

- Do you rinse your mouth after eating?

- Do you use a mouth wash?

- Do you use floss to clean your teeth in between?

- Have you ever noticed bleeding in your gums?

- How often do you visit a dentist to clean your mouth?

\section{RESULT}

The table represents the number of students who used to clean their teeth and tongue daily and also the number of people using mouth wash and the number of students who rinse their mouth after eating. In which 100 of them cleaned their teeth daily and around $96 \%$ of the students used to clean their tongue and $65 \%$ used mouth wash and $64 \%$ rinse their mouth after eating and it was found that $92 \%$ of the people used fluoride containing toothpaste.
How often they visited a dentist

There were around $28 \%$ who visits the dentist once in six months and only $24 \%$ visits once in three months and $33 \%$ once in a year and the number of people who visits once in two years is $6 \%$ and $9 \%$ have not yet visited.

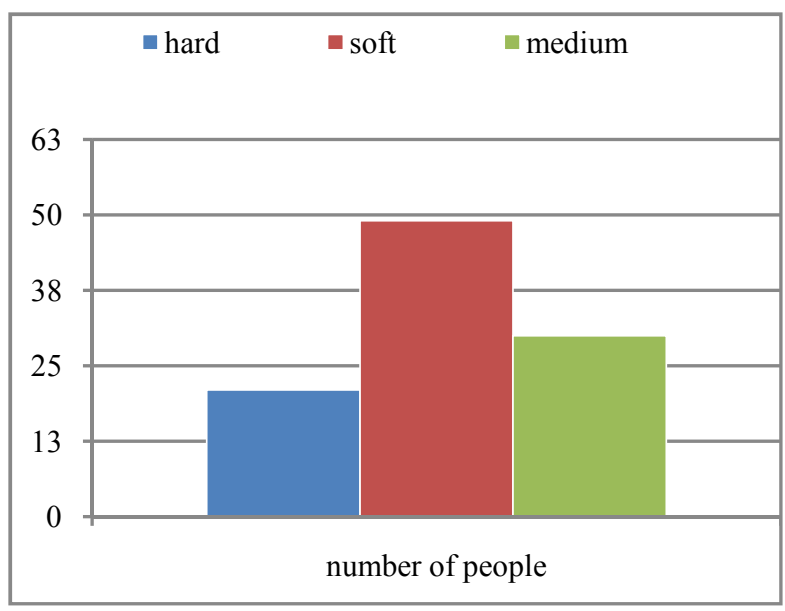

\section{DISCUSSION}

In the present study, most of the students knew at least the basic causes and prevention of dental caries and gum diseases. But knowledge regarding interdental aids was low. Most of the students demonstrated high awareness of the link between oral health and general health and the well being of the rest of the body might help in oral health care and oral self care practice among students, though a majority of the students knew that oral health contributes to esthetics. Over the past 20 years a significant amount of emphasis has been made on

\begin{tabular}{|c|c|c|c|c|c|c|c|c|c|c|}
\hline & $\begin{array}{l}\text { Number of } \\
\text { students who } \\
\text { clean their } \\
\text { teeth daily }\end{array}$ & $\begin{array}{l}\text { Number of } \\
\text { people who } \\
\text { cleans their } \\
\text { tongue }\end{array}$ & $\begin{array}{l}\text { number of } \\
\text { people } \\
\text { using } \\
\text { mouth wash }\end{array}$ & $\begin{array}{l}\text { Numbers of } \\
\text { students who } \\
\text { rinse their } \\
\text { mouth after } \\
\text { eating }\end{array}$ & $\begin{array}{c}\text { Number of } \\
\text { people using } \\
\text { fluoride } \\
\text { containing } \\
\text { toothpaste }\end{array}$ & $\begin{array}{c}\text { Knowled } \\
\text { ge about } \\
\text { dental } \\
\text { health }\end{array}$ & $\begin{array}{l}\text { Knowledge } \\
\text { about } \\
\text { interdental } \\
\text { aids }\end{array}$ & $\begin{array}{c}\text { Number of students } \\
\text { who noticed } \\
\text { bleeding on their } \\
\text { gums }\end{array}$ & $\begin{array}{l}\text { Those who got } \\
\text { their teeth } \\
\text { cleaned } \\
\text { professionally }\end{array}$ & $\begin{array}{l}\text { Those who } \\
\text { cleaned } \\
\text { their teeth } \\
\text { twice daily }\end{array}$ \\
\hline Yes & 100 & 96 & 65 & 64 & 92 & 85 & 56 & 30 & 54 & 51 \\
\hline No & Nil & 4 & 35 & 36 & 8 & 15 & 44 & 70 & 46 & 49 \\
\hline
\end{tabular}

Bar diagram showing the mode they used to clean their teeth and it shows that 87 of them used tooth brush and tooth paste to clean their teeth and 13 of the 100 used tooth brush and tooth powder.

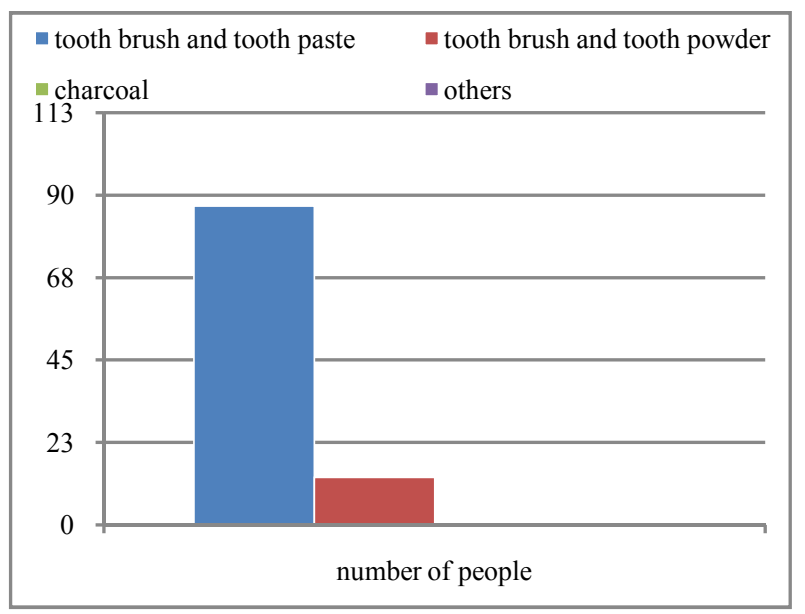

What type of brush they used Around 49\% of them used soft type and only $30 \%$ used medium type and $21 \%$ used hard type of tooth brush.

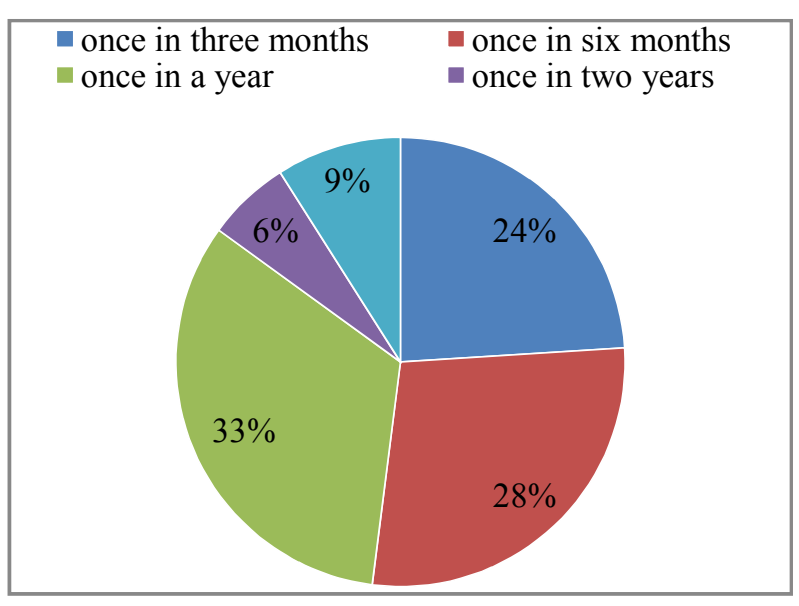

prevention of disease rather than the treatment aspect. Healthy teeth can last us a lifetime with the proper preventive dental care. Preventive oral health Knowledge, Behaviour, and its Practice are more important ways of keeping our teeth healthy. Hence in this study attempts were made to evaluate Knowledge, Attitude and Practice on oral hygiene measures on the population of chennai.The first question was to check the people's knowledge that whether dental problem can effect 
general health or not and around eighty five out 100 had an idea about it and only 15 didn't know about it. The next question was how would they describe their own health of a teeth and gum and 34\% described it as average, $22 \%$ as very good and $33 \%$ as excellent and $11 \%$ as poor. Next question was regarding the use of fluoride containing toothpaste and $92 \%$ answered yes and $8 \%$ said it as no. And the most important thing is among hundred people all off them cleaned their teeth daily and $87 \%$ of them used tooth brush and tooth paste for cleaning their teeth and tooth brush and tooth powder was used by $13 \%$ and none of them used charcoal. The next question was, How often do you clean your teeth and $57 \%$ of the did once daily and $49 \%$ twice daily, and $49 \%$ of them used medium type of tooth brush and $30 \%$ used medium type and $21 \%$ used hard type. And $42 \%$ used horizontal technique and $35 \%$ used combined type and $17 \%$ used vertical type and $6 \%$ used circular type. The next question was when do you changeout tooth brush and $42 \%$ answered every month $29 \%$ once in six months and $29 \%$ used in three months and only $3 \%$ changed once in a year.

And for the question regarding cleaning of their tongue $96 \%$ answered yes, 64\% rinsed their mouth after eating and $36 \%$ were there who don't do so. Most of the people didn't have a idea about what interdental aids were. 56\% didnt have an idea about interdental aids and $44 \%$ knew what it was $33 \%$ used wooden toothpick and $15 \%$ used floss and $27 \%$ used interdental brush. And $70 \%$ of them had noticed bleeding in their gums. 54\% of them had cleaned their tooth professionally and $46 \%$ not yet cleaned. And 33\% of them visited a dentist once in a year to get their mouth cleaned and $28 \%$ once in six months and $24 \%$ once in three months and there was $9 \%$ who has never visited a dentist to get their mouth cleaned.

\section{CONCLUSION}

Most of the students knew the basic knowledge of oral hygiene measures, because about $95 \%$ of students are aware about cleaning teeth, tongue and in using fluoride containing toothpaste but only about $60 \%$ are aware about rinsing mouth after eating, cleaning mouth professionally. Only about $40 \%$ are aware about interdental aids. So more awareness must be created in adolescents of semi-urban areas to ensure oral hygiene health measures.

\section{Reference}

1. Lin S, Mauk A. Diseases in Rural India. Implementing Public Health Interventions in Developing Countries. 105-129.

2. Lateefat S, Musa OI, Kamaldeen AS, Muhammad AS, Saka OI. Determinants of Oral Hygiene Status among Junior Secondary School Students In Ilorin West Local Government Area Of Nigeria. IOSR Journal of Pharmacy and Biological Sciences. 2012; 1: 44-48.

3. National Institute of Dental and Craniofacial Research. Chapter I: Meaning of Oral Health. Accessed [October 7, 2013] at: www.nidcr.nih.gov.
4. World Health Organization (WHO). Oral Health. Accessed at: http://www.who.int/

5. Kwan SY, Petersen PE, Pine CM, Borutta A. Healthpromoting schools: an opportunity for oral health promotion. Bulletin of the World Health Organization. 2005; 83: 677-685.

6. MarcenesW, KassebaumNJ, BernabéE, FlaxmanA, Naghavi M, Lopez A, Murray CJL. Global Burden of Oral Conditions in 1990-2010. A Systematic Analysis. Journal of Dental Research. 2013; 92: 592-597.

7. Al-Mutawa SA, Shyama M, Al-Duwairi, Soparkar P. Oral hygiene status of Kuwaiti school children. Eastern Mediterranean Health Journal. 2011; 17: 387-91.

8. Mbawalla HS, Masalu JR, Åstrøm AN. Sociodemographic and behavioural correlates of oral hygiene status and oral health related quality of life, the Limpopo - Arusha school health project (LASH): A cross-sectional study. BMC Pediatric, 2010; 10: 1-10.

9. Saied-Moallemi Z, Virtanen JI, Vehkalahti MM, Tehranchi A, Murtomaa H: School-based intervention to promote preadolescents' gingival health: a community trial. Community Dentistry and Oral Epidemiology. 2009; 37: 518-526.

10. World Health Organization (WHO): WHO information series on school health, Doc 11: Oral health promotion through schools. Geneva: WHO; 2003: 1-25.

11. Broadbent JM, Thomson WM, Boyens JV, Poulton R. Dental plaque and oral health during the rst 32 years of life. Journal of the American Dental Association. 2011; 142: 415-426.

12. Harikaran AG, Pallavi SK, Hariprakash S, Ashutosh, Nagesh KS. Oral health-related KAP among 11- to 12year old school children in a government-aided missionary school of Bangalore city. Indian Journal of Dental Research, 2008; 19: 236-242.

13. Grewal N, Kaur M. Status of oral health awareness in Indian children as compared to Western children: A thought provoking situation (a pilot study). Journal of Indian Society of Pedodontics and Preventive Dentistry. 2007; 25: 15-19.

14. Oral hygiene awareness and practice among patients attending OPD at Vyas Dental College and Hospital, Jodhpur Nitika Jain, Dipika Mitra, KP Ashok, Jyothi Dundappa, Sweta Soni, Sameer Ahmed Department of Periodontics and Oral Implantology, Vyas Dental College and Hospital, Jodhpur, Rajasthan, India

15. Oral health related knowledge, attitude, and practice among the pre-university students of Mysore city Veera Reddy, Darshana Bennadi. Journal of International Society of Preventive \& Community Dentistry

\section{How to cite this article:}

Shebi S et al (2017) ' Knowledge, Attitude And Practice On Oral Hygiene Measures Among Adolescents In Semi-Urban Areas', International Journal of Current Advanced Research, 06(04), pp. 3371-3373.

DOI: http://dx.doi.org/10.24327/ijcar.2017.3373.0276 